\title{
Predictors and risks of body fat profiles in young New Zealand European, Māori and Pacific women: study protocol for the women's EXPLORE study
}

Rozanne Kruger ${ }^{1 *}$, Sarah P Shultz², Sarah A McNaughton ${ }^{3}$, Aaron P Russell ${ }^{3}$, Ridvan T Firestone ${ }^{4}$, Lily George ${ }^{5}$, Kathryn L Beck', Cathryn A Conlon', Pamela R von Hurst', Bernhard Breier', Shakeela N Jayasinghe', Wendy J O'Brien ${ }^{1}$, Beatrix Jones ${ }^{6}$ and Welma Stonehouse ${ }^{1,7}$

\begin{abstract}
Background: Body mass index (BMI) $\left(\mathrm{kg} / \mathrm{m}^{2}\right)$ is used internationally to assess body mass or adiposity. However, BMI does not discriminate body fat content or distribution and may vary among ethnicities. Many women with normal BMI are considered healthy, but may have an unidentified "hidden fat" profile associated with higher metabolic disease risk. If only BMI is used to indicate healthy body size, it may fail to predict underlying risks of diseases of lifestyle among population subgroups with normal BMI and different adiposity levels or distributions. Higher body fat levels are often attributed to excessive dietary intake and/or inadequate physical activity. These environmental influences regulate genes and proteins that alter energy expenditure/storage. Micro ribonucleic acid (miRNAs) can influence these genes and proteins, are sensitive to diet and exercise and may influence the varied metabolic responses observed between individuals. The study aims are to investigate associations between different body fat profiles and metabolic disease risk; dietary and physical activity patterns as predictors of body fat profiles; and whether these risk factors are associated with the expression of microRNAs related to energy expenditure or fat storage in young New Zealand women. Given the rising prevalence of obesity globally, this research will address a unique gap of knowledge in obesity research.
\end{abstract}

Methods/Design: A cross-sectional design to investigate 675 NZ European, Māori, and Pacific women aged 16-45 years. Women are classified into three main body fat profiles ( $n=225$ per ethnicity; $n=75$ per body fat profile): 1) normal BMI, normal body fat percentage (BF\%); 2) normal BMI, high BF\%; 3) high BMI, high BF\%. Regional body composition, biomarkers of metabolic disease risk (i.e. fasting insulin, glucose, HbA1c, lipids), inflammation (i.e. IL-6, TNF-alpha, hs-CRP), associations between lifestyle factors (i.e. dietary intake, physical activity, taste perceptions) and microRNA expression will be investigated.

Discussion: This research targets post-menarcheal, premenopausal women, potentially exhibiting lifestyle behaviours resulting in excess body fat affecting metabolic health. These behaviours may be characterised by specific patterns of microRNA expression that will be explored in terms of tailored solutions specific to body fat profile groups and ethnicities.

Trial registration: ACTRN12613000714785

Keywords: Body fat profile; Predictors; Overweight and obesity; Metabolic disease risk; MicroRNA; Dietary practices; Physical activity; Taste perception; Women

\footnotetext{
* Correspondence: R.Kruger@massey.ac.nz

'School of Food and Nutrition, Massey University, Auckland, New Zealand

Full list of author information is available at the end of the article
} 


\section{Background}

Obesity has been described as an excess accumulation and storage of fat in the body, typically due to an increase in size and/or number of fat cells. Excess adiposity is generally accepted as an important risk factor for a range of noncommunicable diseases; increased fat in the abdominal area compared with fat around the hips poses greater cardiovascular risks and metabolic dysregulation (Huxley et al. 2010; Martinez et al. 2008; Cameron et al. 2009). Yet, there has been no agreement on defining obesity in terms of body fat percentage (BF\%) (Oliveros et al. 2014). A wide variety of $\mathrm{BF} \%$ cut-off points have been used, varying between 20 to $25 \%$ for men and 30 to $37 \%$ for women (Oliveros et al. 2014). Alternatively, body mass index (BMI) is used worldwide to assess underweight, normal weight, overweight and obesity in adults of both genders (World Health Organisation 2011; Huxley et al. 2010; Gallagher et al. 1996; World Health Organisation 2000). However, BMI does not take into account body fat content or the differential health risks associated with abdominal (central) versus hip (peripheral) fat (Dulloo et al. 2010). There are also concerns regarding the acceptability of BMI as a reference value in varying ethnicities, as overweight and obesity have been defined based on European population data (Deurenberg 2001; World Health Organisation 2011, World Health Organisation 2000). Pacific people, Māori and Asian communities traditionally have larger and smaller body frames, respectively (Swinburn et al. 2004; Huxley et al. 2010; Deurenberg 2001; Rush et al. 2009; Ministry of Health NZ 2009) and subcutaneous fat patterns vary among ethnicities (Deurenberg and Deurenberg-Yap 2003; Okorodudu et al. 2010). Therefore, BMI is unlikely to accurately predict related disease risk profiles among different population subgroups with normal BMI or those that may have different levels of adiposity with a similar BMI (Gallagher et al. 1996; Deurenberg 2001; Ministry of Health NZ 2009).

Adiposity is likely to be overestimated in people with high BMI that have higher lean body mass (e.g. athletes), whilst underestimation is likely in those with lower BMI and less lean body mass (Oliveros et al. 2014; Romero-Corral et al. 2010; Okorodudu et al. 2010). The concept of metabolically obese normal weight individuals has been previously described (Karelis et al. 2004; De Lorenzo et al. 2006), and is associated with increased metabolic dysregulation. This has been referred to as "Normal Weight Obesity" (De Lorenzo et al. 2006) or as will be used in this study, a hidden body fat profile. However, not all individuals with the "hidden fat" profile may be at risk of metabolic disease, and it is unclear from previous studies whether metabolic dysregulation can be explained by high total fat mass, high BF\% or high visceral fat (Oliveros et al. 2014).

During the transition from adolescence to adulthood (15-35 years), women experience larger weight gain than men (Jasik and Lustig 2008). Younger women often practice risky eating (e.g. dieting, fast foods) or lifestyle (e.g. physical inactivity) behaviours and work and environmental pressures may lead to altered food habits resulting in higher $\mathrm{BF} \%$ that may negatively affect their metabolic profiles (Haslam and James 2005; Keskitalo et al. 2008). Furthermore, different taste sensitivities have been shown to influence dietary habits and metabolic health. A higher preference for sweet taste is associated with increased sugary food consumption (Drewnowski et al. 2012), whilst those who are hypersensitive to fatty acids consume less total fat (Stewart et al. 2010). Specific taste perception profiles may therefore lead to increased adiposity and ultimately reduced metabolic and cardiovascular health (Mendoza et al. 2007; Duffey and Popkin 2008). Geneenvironment interactions may also increase the susceptibility of overweight individuals to develop hyperlipidemia, hypertension or diabetes (Martinez et al. 2008; Arkadianos et al. 2007). Excess body fat accumulation is mostly the result of a polygenic syndrome interacting with both dietary and physical activity components of lifestyle (Martinez et al. 2008). The signals delivered by food intake and physical activity regulate genes and proteins that alter energy expenditure/storage (Buttriss 2006). Gene/protein responses to food intake and physical activity vary between individuals; however, the cause is unknown (Martinez et al. 2008). MiRNAs are recently discovered molecules that act as "switches" to "turn on" or "turn off" genes and proteins. They are sensitive to diet and exercise (Güller and Russell 2010) and may influence the varied metabolic response seen between individuals (Davidsen et al. 2011). Recently, specific miRNAs have been suggested as biomarkers for metabolic disease (Heneghan et al. 2011). This unique gene-diet-physical activity relationship might impact on the development of hidden or apparent body fat, with different consequences across ethnic groups and thus requires further investigation (Swinburn et al. 2004; Arkadianos et al. 2007; Deurenberg and Deurenberg-Yap 2003; Di Renzo et al. 2007).

This study will be conducted as a cross-sectional comparative designed study. The primary aim of this study is to explore the metabolic risks and predictive factors associated with the hidden and apparent body fat profiles in 16 to 45 year old (post-menarcheal and premenopausal) NZ European, Mãori and Pacific women. The primary outcomes are:

- Investigating the association between body composition profiles and markers of metabolic disease risk, including glucose, lipid and inflammatory marker profiles;

- Investigating dietary and physical activity patterns as predictive factors associated with body composition profiles; 
- Investigating miRNA expression related to energy expenditure/storage as a predictive factor associated with body composition profiles.

The secondary outcomes are:

- Investigating associations/interactions between dietary and physical activity patterns and miRNA expression and how this may modulate the odds of having a specific body composition profile;

- Investigating taste perceptions as a predictive factor associated with the different body composition profiles;

- Investigating eating behaviour and habits as predictive factors associated with the different body composition profiles;

- Investigating nutrient intake as a predictive factor associated with the different body composition profiles.

We hypothesise that the "hidden fat" profile is associated with increased metabolic disease risk in NZ European, Māori, and Pacific women aged 16 to 45 years. We further hypothesise that for all women, dietary and physical activity patterns are predictors of a particular body composition profile by modulating miRNAs associated with energy expenditure/storage.

\section{Methods/Design \\ Study design}

The Women's EXPLORE ("EXamining Predictors Linking Obesity Related Elements") is a cross-sectional study targeting post-menarcheal, premenopausal NZ women to examine predictors of body composition profiles. Three body composition profile groups will be explored, namely:

"Normal Fat" group - normal BMI $\left(<25 \mathrm{~kg} / \mathrm{m}^{2}\right)$, normal BF\% ( $\geq 22 \%,<30 \%)$;

"Hidden Fat" profile group - normal BMI $\left(<25 \mathrm{~kg} / \mathrm{m}^{2}\right)$, high BF\% ( $\geq 30 \%)$;

"Apparent Fat" profile group - high BMI $\left(\geq 25 \mathrm{~kg} / \mathrm{m}^{2}\right)$, high BF\% ( $\geq 30 \%)$ (Oliveros et al. 2014; Okorodudu et al. 2010; NHLBI Obesity Education Initiative Expert Panel on the Identification Evaluation and Treatment of Overweight and Obesity in Adults 1998).

\section{Participants and sample size}

Study participants are adult NZ women from three ethnic groups (NZ European, Māori, and Pacific Island). A total sample size of 225 women per ethnic group, consisting of 75 per profile group, will provide $80 \%$ power at significance levels of $\mathrm{p}<0.05$ to detect a medium effect size $f$ of 0.25 (G*Power 3.1.2) for comparing the "hidden fat" profile with the other two body composition profiles ("normal fat" and "apparent fat") regarding metabolic disease risk markers, dietary and physical activity patterns, and miRNA expression levels.

The medium effect size is relevant to all variables, and encompasses a variety of scenarios, as we wish to be able to explore how metabolic profile changes with body composition. For example, if the three groups have equally spaced means $(\mu-\Delta, \mu, \mu+\Delta)$, the difference in means will be detected with $80 \%$ power when $\Delta=0.31 \times \sigma$, where $\sigma$ is the within group standard deviation. For cholesterol, where preliminary data suggests $\sigma=0.98 \mathrm{mmol} / \mathrm{L}$, we have $80 \%$ power to detect the difference when $\Delta=0.30 \mathrm{mmol} / \mathrm{L}$. Alternately, if two groups have the same mean $\mu$ and the third has mean $\mu+\Delta, 80 \%$ power is achieved when $\Delta>0.53 \times \sigma$, or $0.52 \mathrm{mmol} / \mathrm{L}$ in the case of cholesterol. A $\Delta=0.30-$ $0.52 \mathrm{mmol} / \mathrm{L}$ is estimated to be associated with a $9-15 \%$ lower relative risk of coronary heart disease (CHD)-related mortality (Gould et al. 2007). For HDL-C where preliminary data suggests $\sigma=0.38 \mathrm{mmol} / \mathrm{L}$ we have $80 \%$ power to detect a difference when $\Delta=0.12-0.20 \mathrm{mmol} / \mathrm{L}$. Every $0.1 \mathrm{mmol} / \mathrm{L}$ increase in HDL-C has been suggested to reduce CHD risk by between $8-15 \%$ (Gordon et al. 1989; Turner et al. 1998). For TG where preliminary data suggests $\sigma=0.45 \mathrm{mmol} / \mathrm{L}$ we have $80 \%$ power to detect a difference when $\Delta=0.14-0.24 \mathrm{mmol} / \mathrm{L}$. Studies in women showed a $1 \mathrm{mmol} / \mathrm{L}$ increase in TG was associated with $37 \%$ increase in risk of CVD (after adjustment for HDL-C and other risk factors)(Austin et al. 1998); $\Delta$ of $0.14-0.24$ is thus estimated to be associated with $5.2-9 \%$ difference in CVD risk.

The power for simple (one variable) logistic regression for the risk of having a "hidden fat" profile among people of normal BMI is equivalent to the power of the independent sample t-test (Vaeth and Skovlund 2004) for comparing the predictor variable mean between the hidden fat and normal fat profiles. With a sample size of 75 per group and equal variance within groups, $80 \%$ power is achieved for differences of $0.46 \sigma$. For instance, preliminary data on total energy expenditure assessed using the Recent Physical Activity Questionnaire (RPAQ) estimates the standard deviation at $5.36 \mathrm{METs}-\mathrm{h} /$ day; if the true difference means between the body composition groups is $2.47 \mathrm{METs}-\mathrm{h} /$ day, the logistic regression coefficient will be significantly nonzero $80 \%$ of the time. Clinically, the difference of 2.47 METs-h/day equates to $\sim 684 \mathrm{~kJ} /$ day $(164 \mathrm{kcal} /$ day)(Besson et al. 2010), which is considered within the target range of recommended energy expended each day in physical activity and/or exercise (Pescatello and American College of Sports Medicine 2014). We will consider logistic regression predictors from the dietary and activity pattern data, and separately for the miRNA measurements.

Based on our pilot study that showed a prevalence of $21 \%$ of NZ European women having a "hidden fat" profile, (Kruger et al. 2010b) a sample of $\sim 1140$ women will need 
to be screened (380 per ethnicity) to find $\sim 75$ women per profile group; or to explore new profiles. The study design and study procedures are illustrated in Figure 1.

Inclusion criteria for women are:

- age (16 to 45 years),

- being post-menarcheal or pre-menopausal (as defined by a continuous regular menstrual cycle for the past one complete year),
- ethnicity (being of NZ European, Māori, or Pacific ethnicity as defined by self-identification and having at least one parent from the same ethnicity).

Exclusion criteria for women are:

- pregnancy and lactation,

- presence of any diagnosed chronic illness particularly affecting metabolic health (e.g. T2DM),

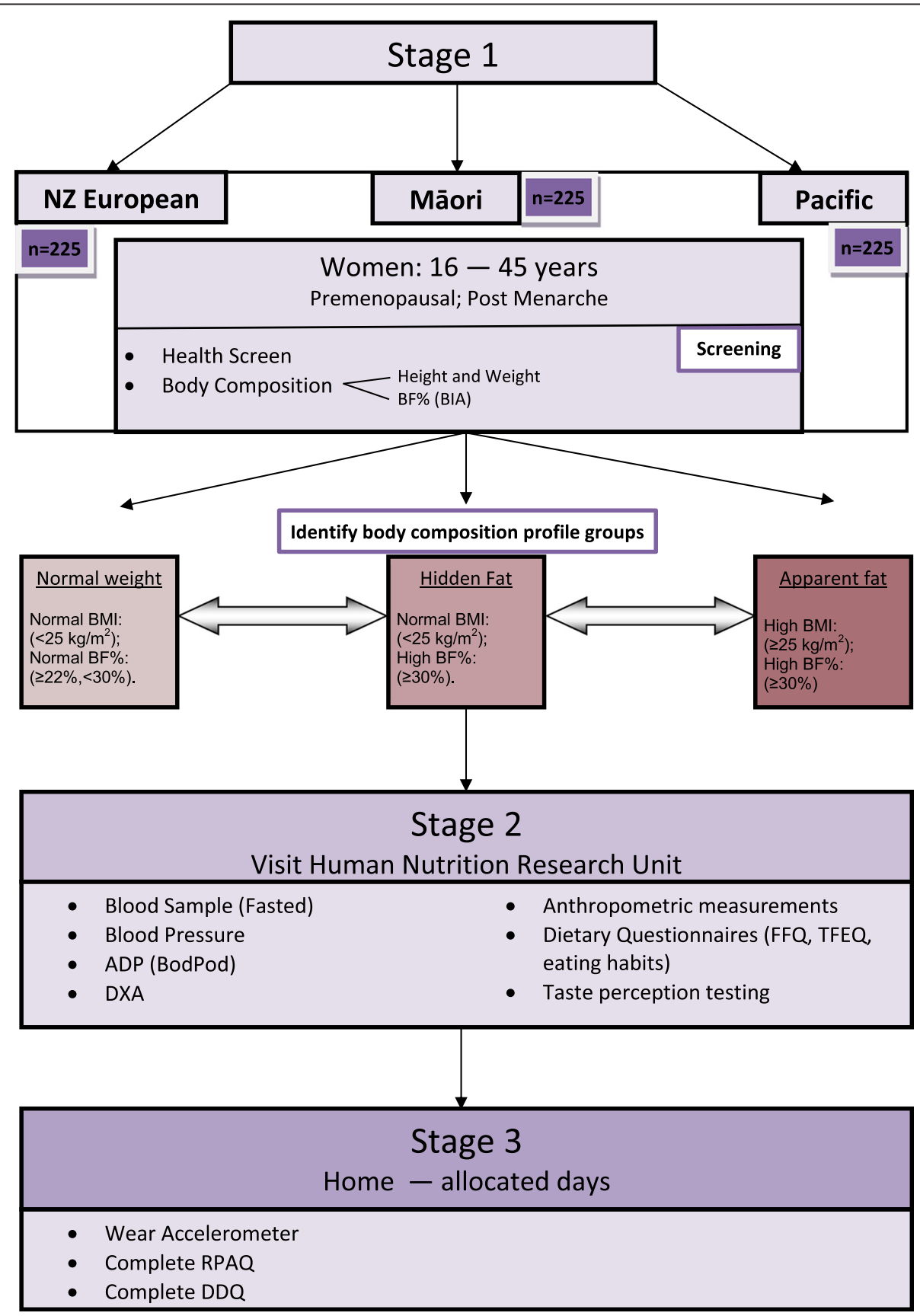

Figure 1 Study design and procedures. 
- presence of dairy allergy as the taste solution is dairy based.

\section{Setting and recruitment}

Women are recruited in Auckland, NZ using media articles and advertising (e.g. in newspapers, magazines, on websites and radio interviews). Posters and flyers are used in a variety of venues including local crèches, primary schools, secondary schools, local businesses and events (e.g. gym's, libraries, and sport events). The study is also advertised using social media (e.g. Facebook, twitter) and via emailing lists (e.g. Massey University staff, student, and previous research participant databases). Potential participants are directed to a study website for further information and to register their interest in the study. For the Māori and Pacific cohorts, recruitment strategies were adapted to be culturally appropriate. A more personal approach with face-toface contact by community liaisons, were used to recruit women. Screening (see Stage 1 under procedures) was conducted within the respective communities and special assistance was provided for participants to travel to Massey University for further data collection (Stage 2).

\section{Procedures}

The study follows a three-staged approach that involves screening (Stage 1), on-site assessments (Stage 2), and at-home assessments (Stage 3) (Figure 1).

\section{Screening (stage 1)}

Women who register interest are provided with an information sheet and asked to complete a consent form and the screening questionnaire. If all the inclusion and exclusion criteria assessed using the screening questionnaire is met, BMI (calculated using height and weight) and BF\% (assessed using bioelectrical impedance (BIA)) are used for preliminary categorisation into the body composition profile groups (described above). The body composition screening is done in person and either at the Human Nutrition Research Unit, Albany campus, Massey University, or off-site.

\section{Assessments (stages 2 and 3)}

Participants recruited in stage 1 are invited to the research unit within 14 days of the start of their last menstrual period (the follicular phase) for testing to avoid the confounding effect of menstrual cycle hormones on taste perception, energy intake and energy expenditure (Davidsen et al. 2007).

Stage 2 of testing involves measurements of anthropometry, body composition, metabolic health, dietary intake, taste perception, and eating behaviour, which are described in detail below.

Stage 3 of assessment is completed at home over a seven day period. Participants wear accelerometers and keep a physical activity diary to assess physical and sedentary activity objectively in real life. At the end of the seven days, participants complete the RPAQ and the dietary diversity questionnaire (DDQ) (see Figure 1).

\section{Measures}

The chosen measures and/or methods used for the various assessments in stages 1, 2 and 3 are listed in Table 1.

\section{Body composition assessment}

Anthropometric measurements include weight, height, waist and hip circumferences using the International Society for the Advancement of Kinanthropometry (ISAK) protocol (Marfell-Jones et al. 2006). Waist-to-hip ratio, waist-to-height ratio and BMI will be derived from these measures and will be used to assess body composition in terms of obesity along with associated disease risk (NHLBI Obesity Education Initiative Expert Panel on the Identification Evaluation and Treatment of Overweight and Obesity in Adults 1998). Fat and lean mass are assessed using BIA (Boneva-Asiova and Boyanov 2008; Ling et al. 2011) for screening and preliminary categorisation into profile groups, and air displacement plethysmography (ADP) (using thoracic gas volume method) for final categorisation (Wingfield et al. 2014; Noreen and Lemon 2006), as well as DXA measurements for regional body composition (Boneva-Asiova and Boyanov 2008).

\section{Metabolic health assessment}

After an overnight fast (no food or beverages, excluding water for 12 hours prior to phlebotomy), blood samples are obtained by registered phlebotomists between 7.00 and 10.00 am and prior to sensory testing. Serum and plasma samples (ethylene diamine tetraacetic acid (EDTA) and heparin) are collected and processed in accordance with pathology laboratory protocols. All samples are frozen in separate aliquots in Eppendorf tubes and stored at $-80^{\circ} \mathrm{C}$ until analysis. Analysis will be carried out by a fully accredited (with IANZ to the ISO 15189) laboratory or by qualified laboratory technicians upon completion of data collection. Biomarkers that will be analysed include plasma levels of glucose, total cholesterol, triglycerides, HDL-C, LDL-C, insulin, leptin, serum hs-CRP, Il-6 and TNF-alpha using commercially available kits or using routine enzymatic assays as published by our team (van Langenberg et al. 2014; Smith et al. 2012). The analyses will be performed using either a Biotek Synergy 2 Plate Reader (Millennium Science, Balwyn, Vic) or a Bioplex 200 plate reader (BioRad Hercules $\mathrm{CA}$ ) depending on the required assay.

Selected miRNA species to assess metabolic disease risk and to explore energy expenditure and storage will be measured as published by our group (Russell et al. 2012; Güller and Russell 2010; Russell et al. 2013; Zacharewicz et al. 
Table 1 Measures and methods

\section{Domain \\ Body composition: anthropometry.}

ean mass.

Metabolic health - biomarkers

Analysis will be conducted by fully accredited laboratory with IANZ to the ISO 15189.

Metabolic health - blood pressure.

Metabolic health - gene expression

Diet Quality

Diet Quality

\section{Measures / methods} $-$ (FFO)

\section{Reference}

(NHLBI Obesity Education Initiative

Expert Panel on the Identification

Evaluation and Treatment of

Overweight and Obesity

in Adults 1998)

(Ling et al. 2011)

(Ogedegbe and Pickering 2010)

(Noreen and Lemon 2006; Wingfield Air displacement Plethysmography (BodPod) et al. 2014)

(Boneva-Asiova and Boyanov 2008) Dual XRay Absorptiometry (DXA) (Hologic using software $\mathrm{V} 42+$ as supplied by the using software
manufacturer). QDR Discovery A, Hologic Inc, Bedford, MA with APEX V. 3.2 software.

Blood sampling to capture plasma glucose, total cholesterol, triacylglyceride, $\mathrm{HDL}$ -

cholesterol, LDL-cholesterol, insulin, serum hs-CRP, II6, TNF-alpha, HbA1C, Leptin, Ghrelin

Blood pressure measurement Riester Ri-Chamion Blood pressure related to metabolic $\mathrm{N}$ digital blood pressure monitor, using one of health.

two arm cuff sizes $(22-32 \mathrm{~cm}$ or $32-48 \mathrm{~cm})$.

(Russell et al. 2012; Zacharewicz et al. 2014 )

miRNA - use specific primer and probes sets as per the manufacturer's instructions (Applied Biosystems, Carlsbad, USA) using an MX3000p thermal cycler system.

miRNA species will be measured using published techniques.

Food Frequency Questionnaire $\quad$ (Ministry of Health NZ 1997;$$
\text { et al. 2010) }
$$

Analysis using Foodworks7 2010 (Xyris Software (Australia) Pty Ltd, Queensland, Australia).

\section{Concept captured}

Body composition.

- Profile in terms of BMI (weight, height)

- Risk in terms of circumferences and ratios (waist, hip, height).

Body composition - (fat and lean mass).

- total

Body composition - (fat and lean mass).

- tota

Body composition - (fat and lean mass).

- total

- regional

Biomarkers related to metabolic health (lipid profile, glucose contro inflammation, hormonal control).

MiRNA related to energy expenditure.

Dietary adequacy

- energy intake

- nutrient intake

Patterns of food and nutrient

intake.

Dietary habits

- eating habits

- meal distribution

- food choices. 
Table 1 Measures and methods (Continued)

Dietary Variety Dietary Diversity Questionnaire Developed in this study; mostly

(DDQ)

based on foods in the FFQ

Dietary Behaviour

Three Factor Eating Questionnaire (TFEQ)

(Stunkard and Messick 1985)

Pescatello and American College WGT3X Actigraph of Sports Medicine 2014)

Physical Activity diary

Physical Activity behaviour

Recent Physical Activity

Questionnaire (RPAQ)

et al. 2004)

$-$

Dietary diversity

Food variety.

Dietary behaviour

- Restraint,

- Disinhibition,

- Hunger.

Objective real life physical activity

Physical activity expenditure

- sedentary activities

- intensity of activity.

Self-reported accelerometer nonwear time

Self-reported intentional exercise

- time

- duration

- type

- intensity.

Self-reported physical activities

- sedentary activities

- time

- intensity.

Sweet and fat taste sensitivity and preference. 
2014). For miRNA analysis, extracted RNA will be reverse transcribed using target specific primers followed by qPCR using target specific probes as published routinely by our group. All qPCR analysis will be performed using the Stratagene MX3000p thermocycler (Stratagene, La Jolla, CA); miRNA results will be normalized to RNA input and log transformed if not normally distributed.

Resting blood pressure measurements are taken whilst sitting, following a 10 minute resting period after taste perception assessments. For blood pressure measurements, an arm cuff is attached to the arm that has not been used for the venepuncture and three measurements are taken consecutively in one minute intervals (Ogedegbe and Pickering 2010).

\section{Dietary intake data}

A 220-item self-administered semi-quantitative food frequency questionnaire (FFQ) is used. The FFQ was adapted from the validated FFQ used in the Adult National Nutrition survey in NZ (Ministry of Health NZ 1997). Changes include an expanded food list to include currently consumed/available foods, additional questions relating specifically to fast food and snack food intakes, changes to the order of questions to improve continuity between questions. The food intake data will be processed using the Foodworks7 (Xyris Software (Australia) Pty Ltd, Queensland, Australia) dietary analysis database utilising FOODfiles 2010 (developed by the NZ Institute for Plant \& Food Research and the NZ Ministry of Health) as the reference food composition table for NZ. Dietary quality and variety of the whole diet will be assessed, including nutritional adequacy and usual intake patterns and adherence to NZ dietary guidelines (Wirt and Collins 2009; Kant and Graubard 2005; Ibiebele et al. 2009). The frequency and patterns of intake of various nutrient-rich/poor dietary components and dietary factors that may affect fat deposition/obesity (e.g. sugar/fat-rich foods, fast foods, etc.) and related habits will be investigated. Foods from the FFQ will be grouped accordingly and factor analysis will be used to determine dietary pattern scores (McNaughton 2011; Mishra et al. 2010). Dietary variety will be assessed using dietary diversity scores and food variety scores to explore the variety of nutritious and non-nutritious foods (Ruel 2003; Murphy et al. 2006). Eating habits, meal patterns and food choices are explored using a self-developed and validated (during the current study) questionnaire, providing descriptive data of the women's dietary practices.

Dietary behaviour is assessed using the validated TFEQ (Stunkard and Messick 1985; Bond et al. 2001) to measure three eating behaviour traits. The three factors are cognitive dietary restraint (Restraint), disinhibition of control (Disinhibition) and susceptibility to hunger (Hunger) by calculating scores for the dimensions and their sub-categories.

\section{Sensory testing}

Sensitivity and preferences of sweet and fat taste are assessed. Participants rate the intensity and hedonic preference of five sucrose and dairy samples on a general labelled magnitude scale (gLMS) (Bartoshuk et al. 2004; Lim et al. 2008).

\section{Physical activity}

A w-GT3X triaxial accelerometer (Actigraph, Pensacola, FL) secured to a waist belt, is worn for seven days, with a minimum of $10 \mathrm{~h}$ per day, to measure all components of physical activity and energy expenditure. Participants maintain their regular physical activity, whilst keeping a diary of times when the device is not worn. At least three full week and two weekend days is required for analysis. Physical activity counts will be calculated from raw data as the square root of the sum squared of activity counts, and will be categorized using metabolic equivalents (METs), as defined by the American College of Sports Medicine guidelines (Pescatello and American College of Sports Medicine 2014). Activities will be classified as light or sedentary (1.1-2.9 METs), moderate (3.0-6.0 METs), or vigorous (>6.0 METs). A physical activity diary is kept to record periods of non-wear and of intentional exercise. A self-reported RPAQ (Besson et al. 2010) is completed at the end of seven days with reference to the previous four weeks, allowing, together with the diary, a specific interpretation of the accelerometry counts.

\section{Data handling and statistical analysis}

Statistical analysis will be performed using IBM SPSS statistics (IBM Corporation, New York, USA). Descriptive statistics will be used to describe the baseline population using mean (standard deviation), median (25, 75 percentile) or frequencies summary statistics. Normality of distribution will be evaluated using the KolmogorovSmirnov test and examining normality plots. Nonnormally distributed variables will be transformed into approximately normal distributions by logarithmic transformations and again tested for normality. Primary statistical analyses will involve ANOVA tests with post-hoc analysis and Bonferoni adjustments comparing body composition profile groups regarding metabolic disease risk markers and dietary and physical activity patterns and miRNA levels; multiple logistic regression analysis to determine odds ratios of having a "hidden body fat" profile based on dietary and physical activity patterns; and, separately, miRNA expression levels. Principal components analysis will be performed on the miRNA data using the PCP directive in GenStat to identify linear combinations of the miRNAs that account for most of the variation between individuals (Zacharewicz et al. 2014); and Pearson correlations to determine correlation 
coefficients between dietary and physical activity patterns and miRNA expression profiles. A p-value of $<0.05$ will be considered significant.

\section{Ethics}

Ethical approval was obtained from the Massey University Human Ethics Committee: (Southern A), Reference No.13/13.

\section{Discussion}

An ethnic-specific focus aimed at weight maintenance has been recommended from previous NZ research (Metcalf et al. 2000). Overweight or obesity is a continual process and the effects of inappropriate lifestyle behaviour may often be missed when strictly assessing BMI as an indicator of over-nutrition. BMI provides only a crude measure of body fatness as it does not distinguish between weight associated with muscle or with fat. However, it appears to remain a useful estimate of the proportion of the population with increased risk of health conditions associated with obesity (World Health Organisation 2000), but may not be able to predict disease risk in those with normal BMI and varying adiposity.

Previous research has shown that a significant proportion of individuals with normal weight and subsequent normal BMI values had excessive body fat or "hidden" fat (Kruger et al. 2010a; De Lorenzo et al. 2006; RomeroCorral et al. 2010; Kruger et al. 2010b). This "hidden fat" profile may be linked with early inflammation and may be a key factor in the emerging epidemic of obesity and related disease risk (De Lorenzo et al. 2006; De Lorenzo et al. 2007). Pilot study data from our laboratory (Kruger et al. 2010a; Kruger et al. 2010b) revealed that in a free-living population $(\mathrm{N}=116)$ of 18 to 44 year old NZ European women, $21.4 \%$ had a "hidden fat" profile and subsequent increased metabolic disease risk (identified through elevated fasting plasma leptin and insulin concentrations) and higher levels of sedentary lifestyle parameters.

Although a few studies have explored normal weight obesity (Marques-Vidal et al. 2008; Di Renzo et al. 2010; Romero-Corral et al. 2010; Karelis et al. 2004), not many studies have been specifically conducted to explore metabolic disease risk associated with high body fat (hidden or apparent), in premenopausal women. The typical central fat deposition following menopause and/or ageing may be absent in premenopausal women, despite the fact that women steadily gain weight from menarche to adulthood. It is therefore unclear where the hidden fat is situated in these women, especially if they are slender. It may be that excess fat in a lean person is hidden in the abdomen or elsewhere where it could pose health risks and cause metabolic dysregulation (Di Renzo et al. 2006; Huxley et al. 2010; Martinez et al. 2008; Cameron et al. 2009).

\section{Implications}

The presence of normal weight obesity varies between 2 to $28 \%$ in women (Oliveros et al. 2014). The origins are unclear and may be due to environmental as well as genetic factors (Oliveros et al. 2014; Karelis et al. 2004). Common recommendations for appropriate dietary or lifestyle behaviours may be ineffective due to individual genetic variation. Dietary or physical activity behaviours may influence molecular mechanisms controlling metabolic activity and gene expression. MiRNAs can regulate the gene and protein networks that control substrate utilization and storage. Differences in behaviour that impact on miRNA expression need to be identified in different body composition profiles. Identifying these differences may assist in developing preventive recommendations (Arkadianos et al. 2007), and need to be specific to the locality and culture of the target population (Swinburn et al. 2004).

Because we do not know if and where slender women of different ethnicities with a normal BMI store hidden fat, it is important to identify this and its possible impact on women's health. It is equally important to consider these issues in women with apparent fat and normal BF\% to be able to make comparisons and explore tailored solutions. Our study will address a unique gap in health research knowledge by investigating multi-ethnic populations in NZ, identifying important physiological and behavioural predictors of metabolic disease risk. This research will assist in providing an important piece of the metabolic health versus body composition puzzle to fall into place and generate new pathways for treatment or early intervention.

\section{Abbreviations}

ADP: Air displacement plethysmography; BF\%: Body fat percentage; BIA: Bioelectrical impedance analysis; BMI: Body mass index;

CVD: Cardiovascular disease; DDQ: Dietary diversity questionnaire; EDTA: Ethylene diamine tetra acetic acid; FFQ: Food frequency questionnaire; gLMS: General labelled magnitude scale; ISAK: International society for the advancement of kinanthropometry; miRNA: micro ribonucleic acid; METs: Metabolic equivalents; NZ: New Zealand; RPAQ: Recent Physical Activity Questionnaire; T2DM: Type two diabetes mellitus; TFEQ: Three factor eating questionnaire.

\section{Competing interests}

The authors declare that they have no competing interests.

\section{Authors' contributions}

RK conceptualised the study. RK and WS designed the overall research study and obtained ethical approval. RK, SM and KB advise on the dietary measures, BHB and SJ advise on the taste perception assessment and metabolic health measures, AR advises on the miRNA protocols and analysis, SS and WO'B advise on the physical activity section, BJ and WS advise on statistical analysis, RF and LG advise on and assist with cultural aspects and recruitment; RK, SJ, WO'B, KB, CC, PVH conduct the study including recruitment and data collection. RK drafted the manuscript. All authors were involved in revising the manuscript and all read and approved the final manuscript.

\section{Acknowledgements}

This research study is funded by the Nutricia Research Foundation and Lotteries Health Research, and the Massey University Postgraduate Fund from the School of Food and Nutrition. 
The funders will be acknowledged in all manuscripts or presentations. Data will be collected, analysed and interpreted independently of any funding bodies. Results will be submitted to scientific journals regardless of the outcome.

We would like to thank all the women who are participating in this study. We gratefully acknowledge our research team and all the students participating in this study: MSc candidates AJ Hepburn, Zara Houston, Sarah Philipsen, Richard Swift, Andrea Fenner, Maria Casale, and Jenna Schrijvers; as well as our research assistants Chelsea Symons, Carmel Trubuhovich, Owen Mugridge, Sara Bodel, PC Tong, Poihaere Ratima, and Metua Bates. We would also like to acknowledge two research interns, Tineke Haakma and Kathrin Nenz, for their assistance with data collection.

\section{Author details}

'School of Food and Nutrition, Massey University, Auckland, New Zealand. ${ }^{2}$ School of Sport and Exercise, Massey University, Wellington, New Zealand. ${ }^{3}$ Centre for Physical Activity and Nutrition Research, School of Exercise and Nutrition Sciences, Deakin University, Melbourne, Australia. ${ }^{4}$ Centre for Public Health Research, Massey University, Wellington, New Zealand. ${ }^{5}$ Office of Assistant Vice Chancellor Mãori, Pacific \& New Migrants, Massey University, Auckland, New Zealand. ${ }^{6}$ Institute of Information and Mathematical Sciences, Massey University, Auckland, New Zealand. ${ }^{7}$ Commonwealth Scientific and Industrial Research Organisation, Food and Nutrition Flagship, Adelaide, Australia.

Received: 24 October 2014 Accepted: 3 March 2015 Published online: 14 March 2015

\section{References}

Arkadianos I, Valdes AM, Marinos E, Florou A, Gill RD, Grimaldi KA (2007) Improved weight management using genetic information to personalize a calorie controlled diet. Nutr J 6:29, doi:10.1186/1475-2891-6-29

Austin MA, Hokanson JE, Edwards KL (1998) Hypertriglyceridemia as a cardiovascular risk factor. Am J Cardiol 81(4A):7B-12B

Bartoshuk LM, Duffy VB, Green BG, Hoffman HJ, Ko CW, Lucchina LA, Marks LE, Snyder DJ, Weiffenbach JM (2004) Valid across-group comparisons with labeled scales: the gLMS versus magnitude matching. Physiol Behav 82(1):109-114, doi:10.1016/j.physbeh.2004.02.033

Besson H, Brage S, Jakes RW, Ekelund U, Wareham NJ (2010) Estimating physical activity energy expenditure, sedentary time, and physical activity intensity by self-report in adults. Am J Clin Nutr 91(1):106-114, doi:10.3945/ ajcn.2009.28432

Bond MJ, McDowell AJ, Wilkinson JY (2001) The measurement of dietary restraint, disinhibition and hunger: an examination of the factor structure of the Three Factor Eating Questionnaire (TFEQ). Int J Obes Relat Metab Disord 25(6):900-906, doi:10.1038/sj.ijo.0801611

Boneva-Asiova Z, Boyanov MA (2008) Body composition analysis by leg-to-leg bioelectrical impedance and dual-energy $\mathrm{X}$-ray absorptiometry in non-obese and obese individuals. Diabetes Obes Metab 10(11):1012-1018, doi:10.1111/ j.1463-1326.2008.00851.x

Buttriss $J \mathrm{~L}$ (2006) Diet-gene interactions and current EU research: Something for everybody! Nutr Bull 31(1):65-68

Cameron AJ, Dunstan DW, Owen N, Zimmet PZ, Barr EL, Tonkin AM, Magliano DJ, Murray SG, Welborn TA, Shaw JE (2009) Health and mortality consequences of abdominal obesity: evidence from the AusDiab study. Med J Aust 191(4):202-208

Davidsen L, Vistisen B, Astrup A (2007) Impact of the menstrual cycle on determinants of energy balance: a putative role in weight loss attempts. Int J Obes (Lond) 31(12):1777-1785, doi:10.1038/sj.ijo.0803699

Davidsen PK, Gallagher IJ, Hartman JW, Tarnopolsky MA, Dela F, Helge JW, Timmons JA, Phillips SM (2011) High responders to resistance exercise training demonstrate differential regulation of skeletal muscle microRNA expression. J Appl Physiol 110(2):309-317

De Lorenzo A, Del Gobbo V, Premrov MG, Bigioni M, Galvano F, Di Renzo L (2007) Normal-weight obese syndrome: early inflammation? Am J Clin Nutr 85(1):40-45

De Lorenzo A, Martinoli R, Vaia F, Di Renzo L (2006) Normal weight obese (NWO) women: an evaluation of a candidate new syndrome. Nutr Metab Cardiovasc Dis 16(8):513-523

Deurenberg P (2001) Universal cut-off BMI points for obesity are not appropriate. Br J Nutr 85(2):135-136
Deurenberg P, Deurenberg-Yap M (2003) Validity of body composition methods across ethnic population groups. Forum Nutr 56:299-301

Di Renzo L, Bigioni M, Del Gobbo V, Premrov MG, Barbini U, Di Lorenzo N, De Lorenzo A (2007) Interleukin-1 (IL-1) receptor antagonist gene polymorphism in normal weight obese syndrome: relationship to body composition and IL-1alpha and beta plasma levels. Pharmacol Res 55(2):131-138

Di Renzo L, Del Gobbo V, Bigioni M, Premrov MG, Cianci R, De Lorenzo A (2006) Body composition analyses in normal weight obese women. Eur Rev Med Pharmacol Sci 10(4):191-196

Di Renzo L, Galvano F, Orlandi C, Bianchi A, Di Giacomo C, La Fauci L, Acquaviva $\mathrm{R}$, De Lorenzo A (2010) Oxidative stress in normal-weight obese syndrome. Obesity 18(11):2125-2130

Drewnowski A, Mennella JA, Johnson SL, Bellisle F (2012) Sweetness and food preference. J Nutr 142(6):1142S-1148S, doi:10.3945/jn.111.149575

Duffey KJ, Popkin BM (2008) High-fructose corn syrup: is this what's for dinner? Am J Clin Nutr 88(6):1722S-1732S, doi:10.3945/ajen.2008.25825C

Dulloo AG, Jacquet J, Solinas G, Montani JP, Schutz Y (2010) Body composition phenotypes in pathways to obesity and the metabolic syndrome. Int J Obes (Lond) 34(Suppl 2):S4-17, doi:10.1038/ijo.2010.234

Gallagher D, Visser M, Sepúlveda D, Pierson RN, Harris T, Heymsfield SB (1996) How useful is body mass index for comparison of body fatness across age, sex, and ethnic groups? Am J Epidemiol 143(3):228-239

Gordon DJ, Probstfield JL, Garrison RJ, Neaton JD, Castelli WP, Knoke JD, Jacobs DR Jr, Bangdiwala S, Tyroler HA (1989) High-density lipoprotein cholesterol and cardiovascular disease. Four prospective American studies. Circulation 79(1):8-15

Gould AL, Davies GM, Alemao E, Yin DD, Cook JR (2007) Cholesterol reduction yields clinical benefits: meta-analysis including recent trials. Clin Therap 29(5):778-794, http://dx.doi.org/10.1016/j.clinthera.2007.05.012

Güller I, Russell AP (2010) MicroRNAs in skeletal muscle: their role and regulation in development, disease and function. J Physiol 588(21):4075-4087

Haslam DW, James WPT (2005) Obesity. Lancet 366(9492):1197-1209

Heneghan HM, Miller N, McAnena OJ, O'Brien T, Kerin MJ (2011) Differential miRNA expression in omental adipose tissue and in the circulation of obese patients identifies novel metabolic biomarkers. J Clin Endocrinol Metabol 96(5):E846-E850

Huxley R, Mendis S, Zheleznyakov E, Reddy S, Chan J (2010) Body mass index, waist circumference and waist:hip ratio as predictors of cardiovascular risk-a review of the literature. Eur J Clin Nutr 64(1):16-22

Ibiebele TI, Parekh S, Mallitt KA, Hughes MC, O'Rourke PK, Webb PM (2009) Reproducibility of food and nutrient intake estimates using a semiquantitative FFQ in Australian adults. Public Health Nutr 12(12):2359-2365, doi:10.1017/s1368980009005023

Jasik CB, Lustig RH (2008) Adolescent obesity and puberty: the "perfect storm". Ann N Y Acad Sci 1135:265-279, doi:10.1196/annals.1429.009

Kant AK, Graubard BI (2005) A comparison of three dietary pattern indexes for predicting biomarkers of diet and disease. J Am Coll Nutr 24(4):294-303

Karelis AD, St-Pierre DH, Conus F, Rabasa-Lhoret R, Poehlman ET (2004) Metabolic and body composition factors in subgroups of obesity: what do we know? J Clin Endocrinol Metab 89(6):2569-2575, doi:10.1210/jc.2004-0165

Keskitalo K, Silventoinen K, Tuorila H, Perola M, Pietilainen KH, Rissanen A, Kaprio $J$ (2008) Genetic and environmental contributions to food use patterns of young adult twins. Physiol Behav 93(1-2):235-242

Kruger R, Beck KL, Conlon CA, Stonehouse W (2010a) Normal BMI, but fat. In: Proceedings of the Nutrition Society of New Zealand. Nutrition Society of New Zealand, Wellington, p 116

Kruger R, Beck KL, Conlon CA, Stonehouse W (2010b) Profiling the skinny fat woman. In: McMath K (ed) Proceedings of the New Zealand Institute of Food Science and Technology Conference. The New Zealand Institute of Food Science and Technology Inc, Auckland, p 14

Lim J, Urban L, Green BG (2008) Measures of individual differences in taste and creaminess perception. Chem Senses 33(6):493-501, doi:10.1093/chemse/bjn016

Ling CHY, de Craen AJM, Slagboom PE, Gunn DA, Stokkel MPM, Westendorp RGJ, Maier AB (2011) Accuracy of direct segmental multi-frequency bioimpedance analysis in the assessment of total body and segmental body composition in middle-aged adult population. Clin Nutr 30(5):610-615, doi:10.1016/j. clnu.2011.04.001

Marfell-Jones M, Olds T, Stewart A, Carter L (2006) International standards for anthropometric assessment. ISAK, Potchefstroom

Marques-Vidal P, Chiolero A, Paccaud F (2008) Large differences in the prevalence of normal weight obesity using various cut-offs for excess body fat. E Spen Eur E J Clin Nutr Metab 3(4):e159-e162 
Martinez JA, Parra MD, Santos JL, Moreno-Aliaga MJ, Marti A, Martinez-Gonzalez MA (2008) Genotype-dependent response to energy-restricted diets in obese subjects: Towards personalized nutrition. Asia Pac J Clin Nutr 17(Suppl 1):119-122

McNaughton SA (2011) Understanding the eating behaviors of adolescents: application of dietary patterns methodology to behavioral nutrition research. J Am Diet Assoc 111(2):226-229

Mendoza JA, Drewnowski A, Christakis DA (2007) Dietary energy density is associated with obesity and the metabolic syndrome in U.S. adults. Diabetes Care 30(4):974-979, doi:10.2337/dc06-2188

Metcalf PA, Scragg RK, Willoughby P, Finau S, Tipene-Leach D (2000) Ethnic differences in perceptions of body size in middle-aged European, Maori and Pacific people living in New Zealand. Int J Obes Relat Metab Disord 24(5):593-599

Ministry of Health NZ (1997) Food Comes First : Methodologies for the National Nutrition Survey of New Zealand. Public Health Report number 2. Ministry of Health, Wellington, New Zealand

Ministry of Health NZ (2009) Clinical guidelines for weight management in New Zealand adults. Ministry of Health, Wellington, New Zealand

Mishra GD, McNaughton SA, Ball K, Brown WJ, Giles GG, Dobson AJ (2010) Major dietary patterns of young and middle aged women: results from a prospective Australian cohort study. Eur J Clin Nutr 64(10):1125-1133

Murphy SP, Foote JA, Wilkens LR, Basiotis PP, Carlson A, White KK, Yonemori KM (2006) Simple measures of dietary variety are associated with improved dietary quality. J Am Diet Assoc 106(3):425-429, doi:10.1016/j.jada.2005.12.003

$\mathrm{NHLBI}$ Obesity Education Initiative Expert Panel on the Identification Evaluation and Treatment of Overweight and Obesity in Adults (1998) Clinica guidelines on the identification, evaluation, and treatment of overweight and obesity in adults-the evidence report. National Institutes of Health. Obes Res 6(Suppl 2):51S-209S

Noreen EE, Lemon PWR (2006) Reliability of air displacement plethysmography in a large, heterogeneous sample. Med Sci Sports Exerc 38(8):1505-1509, doi:10.1249/01.mss.0000228950.60097.01

Ogedegbe G, Pickering T (2010) Principles and techniques of blood pressure measurement. Cardiol Clin 28(4):571-586, doi:10.1016/j.ccl.2010.07.006

Okorodudu DO, Jumean MF, Montori VM, Romero-Corral A, Somers VK, Erwin PJ, Lopez-Jimenez F (2010) Diagnostic performance of body mass index to identify obesity as defined by body adiposity: a systematic review and meta-analysis. Int J Obes (Lond) 34(5):791-799, doi:10.1038/ijo.2010.5

Oliveros E, Somers VK, Sochor O, Goel K, Lopez-Jimenez F (2014) The concept of normal weight obesity. Prog Cardiovasc Dis 56(4):426-433, doi:10.1016/j. pcad.2013.10.003

Pescatello LS, American College of Sports Medicine (2014) ACSM's guidelines for exercise testing and prescription, 9th edn. Wolters Kluwer/Lippincott Williams \& Wilkins Health, Philadelphia

Romero-Corral A, Somers VK, Sierra-Johnson J, Korenfeld Y, Boarin S, Korinek J, Jensen MD, Parati G, Lopez-Jimenez F (2010) Normal weight obesity: a risk factor for cardiometabolic dysregulation and cardiovascular mortality. Eur Heart J 31(6):737-746, doi:10.1093/eurheartj/ehp487

Ruel MT (2003) Is dietary diversity an indicator of food security or dietary quality? A review of measurement issues and research needs. Food Nutr Bull 24(2):231-232

Rush EC, Freitas I, Plank LD (2009) Body size, body composition and fat distribution: comparative analysis of European, Maori, Pacific Island and Asian Indian adults. Br J Nutr 102(4):632-641, doi:10.1017/S0007114508207221

Russell AP, Lamon S, Boon H, Wada S, Guller I, Brown EL, Chibalin AV, Zierath JR, Snow RJ, Stepto N, Wadley GD, Akimoto T (2013) Regulation of miRNAs in human skeletal muscle following acute endurance exercise and short-term endurance training. J Physiol 591(Pt 18):4637-4653, doi:10.1113/jphysiol.2013.255695

Russell AP, Wada S, Vergani L, Hock MB, Lamon S, Léger B, Ushida T, Cartoni R, Wadley G, Hespel P, Kralli A, Soraru G, Angelini C, Akimoto T (2012) Disruption of skeletal muscle mitochondrial network genes and miRNAs in amyotrophic lateral sclerosis. Neurobiol Dis 49C:107-11

Smith KJ, Blizzard L, McNaughton SA, Gall SL, Dwyer T, Venn AJ (2012) Daily eating frequency and cardiometabolic risk factors in young Australian adults: cross-sectional analyses. Br J Nutr 108(6):1086-1094, doi:10.1017/ s0007114511006398

Stewart JE, Feinle-Bisset C, Golding M, Delahunty C, Clifton PM, Keast RS (2010) Oral sensitivity to fatty acids, food consumption and BMI in human subjects. $\mathrm{Br}$ J Nutr 104(1):145-152, doi:10.1017/s0007114510000267
Stunkard AJ, Messick S (1985) The three-factor eating questionnaire to measure dietary restraint, disinhibition and hunger. J Psychosom Res 29(1):71-83

Swinburn BA, Caterson I, Seidell JC, James WPT (2004) Diet, nutrition and the prevention of excess weight gain and obesity. Public Health Nutr $7((1 \mathrm{~A}): 123-146$

Turner RC, Millns H, Neil HA, Stratton IM, Manley SE, Matthews DR, Holman RR (1998) Risk factors for coronary artery disease in non-insulin dependent diabetes mellitus: United Kingdom Prospective Diabetes Study (UKPDS: 23). BMJ 316(7134):823-828

Vaeth M, Skovlund E (2004) A simple approach to power and sample size calculations in logistic regression and Cox regression models. Stat Med 23(11):1781-1792, doi:10.1002/sim.1753

van Langenberg DR, Della Gatta P, Warmington SA, Kidgell DJ, Gibson PR, Russell AP (2014) Objectively measured muscle fatigue in Crohn's disease: correlation with self-reported fatigue and associated factors for clinical application. J Crohns Colitis 8(2):137-146, doi:10.1016/j.crohns.2013.07.006

Wingfield HL, Smith-Ryan AE, Woessner MN, Melvin MN, Fultz SN, Graff RM (2014) Body composition assessment in overweight women: validation of air displacement plethysmography. Clin Physiol Funct Imaging 34(1):72-76, doi:10.1111/cpf.12067

Wirt A, Collins CE (2009) Diet quality-what is it and does it matter? Public Health Nutr 12(12):2473-2492, doi:10.1017/s136898000900531x

World Health Organisation (2000) Obesity: Preventing and Managing the Global Epidemic. WHO Technical report series No. 894. World Health Organisation, Geneva

World Health Organisation (2011) Obesity and overweight: fact sheet No 311 World Health Organisation, Geneva

Zacharewicz E, Della Gatta P, Reynolds J, Garnham A, Crowley T, Russell AP et al. (2014) Identification of MicroRNAs linked to regulators of muscle protein synthesis and regeneration in young and old skeletal muscle. PLOS ONE 9 (12). doi:10.1371/journal.pone.0114009.

\section{Submit your manuscript to a SpringerOpen ${ }^{\circ}$ journal and benefit from:}

- Convenient online submission

$\checkmark$ Rigorous peer review

- Immediate publication on acceptance

- Open access: articles freely available online

- High visibility within the field

- Retaining the copyright to your article

Submit your next manuscript at $>$ springeropen.com 